\title{
Juegos referenciales y configuraciones espaciales en el universo cortazariano: «Ahí, pero dónde, cómo»
}

\author{
Alma Rosa Aguilar \\ Universidad Nacional de Costa Rica
}

Il n'y a de fantastique que d'un espace, en son coeur et par son biais. Le texte, et cel a ra de soil'inage, fixe tout particulièrement l'attention sur le lieu d'apparition du phénomène perturbateur. Charles Grivel, Fantastique-Fiction.

En los cuentos de Julio Cortázar lo fantástico nace esencialmente de un elemento predominante y recurrente: el tratamiento particular de un dominio de referencia, sea el tiempo. como en «El otro cielo», sea la persona, como en «Lejana». También juega un papel crucial en la creación de los universos fantásticos cortazarianos la referencia al espacio, en especial en muchos relatos que conforman el volumen Pasajes.

El espacio, en tanto que campo conceptual, funciona como material fundamental en la construcción de lo fantástico. La concepción de un sistema de espacialidad para construir el universo físico en que se inscribe la historia supone un tratamiento muy particular del lenguaje, el cual se enriquece por las relaciones que unen las configuraciones espaciales entre sí, pero también con los otros componentes de la obra: tiempo, personajes y acciones. La significación de dicho sistema de relaciones se organiza en torno al valor simbólico del aquí y el allá. de lo cerrado y lo abierto, de lo real y lo irreal: de la singular y armoniosa combinación de los opuestos surge el universo fantástico. 
El texto invita a pensar el espacio de una manera no convencional; elabora un programa de interpretación de la significación, del valor simbólico de los espacios creados, y de la localización, a partir de la creación de imágenes difusas. Propone la reconstrucción de los itinerarios trazados a lo largo del texto por medio de la identificación de elementos diversos como espacio inicial, trayecto o recorrido, meta, incluyendo los fenómenos de concomitancia y superposición de los espacios.

El diseño del espacio cortazariano, sumamente complejo, se constituye en material de lo fantástico gracias al trabajo conceptual.y lingüístico puesto en ejecución en la creación de los dispositivos de espacialización en el relato, del conjunto de trayectos semánticos que definen el universo de la ficción. Pero la propuesta cortazariana consiste en un sistema de relaciones sujeto-espacio; los mecanismos de localización utilizados, además de identificar las entidades en los diferentes lugares, especifican la injerencia de sus propiedades en el trayecto, evolución y destino de los personajes.

El texto juega así incesantemente al desafío conceptual con el espacio para posibilitar «la realización del pasaje»; motivo que, asociado a la espacialidad (y sus relaciones con el conjunto de los componentes narrativos), constituye la línea directriz de esos relatos.

Los protagonistas efectúan un ir y venir permanente de un universo a otro — un pasaje- y la forma de su realización sugiere un nuevo orden de la espacialidad, de la temporalidad y de la concepción del sujeto. El pasaje sobreviene, se impone, es el camino del héroe hacia su plenitud, su objeto de deseo, el equilibrio momentáneo del ser, la efímera estabilidad, aunque su búsqueda no sea consciente y voluntaria. Dicho pasaje, motivo general del volumen. establece una relación entre dos regiones, dos universos y dos tiempos diferentes, permitiendo así al individuo escaparse del ámbito cotidiano y social, para él, indiferente y extraño. Los protagonistas, por su parte, tienen actitudes específicas hacia cada uno de esos dos universos; se integran difícilmente en su entorno inmediato y nunca logran insertarse en su 
medio social original. Dichosamente para estos, por momentos, las fronteras entre los dos universos se borran como consecuencia de la activación de un sistema relacional interno del texto que permite establecer puentes iluminantes de contacto entre los puntos inicial y final del pasaje.

La figuración construida con la tríada tiempo-espacio-personaje alcanza una función central al ser puesta en relación condos elementos fundadores de la significación textual: la dualidad y el deseo. Como resultado de esa fusión, la figura del pasaje actualiza los principios de la dualidad, fenómeno constitutivo del ser y del deseo, móvil de la existencia, generador de experiencias en otros espacios.

En varios textos del volumen Pasajes, en la elaboración conceptual efectuada para construir los espacios, a menudo dicotómicos, en los cuales evolucionan los personajes, se revela una enorme variedad de los procedimientos lingüísticos bajo el común denominador del motivo de la dualidad dispuesto en forma de oposición. Sin embargo, la espacialidad es construida de forma particular en cada cuento, revelándose así como una materia prima riquísima que permitió a Cortázar explotar este recurso en sus múltiples dimensiones, con una imaginación y una creatividad poco comunes.

En «Ahí, pero dónde, cómo» ${ }^{1}$, el procedimiento de construcción de los espacios, por encima de los otros componentes, constituye la característica más evidente de lo fantástico y la línea directriz del relato. El rol del espacio está muy ligado a la percepción del otro en tanto que componente de la dualidad; «el otro» se halla situado en un lugar distante, cuya aprehensión determina la búsqueda del protagonista:

mucho peor es este paso del sueño a las palabras, el agujero entre lo que todavía sigue ahí pero se va entregando más y más a los nítidos filos de las cosas de este lado, al cuchillo de las palabras

1. Julio Cortizar. Los relatos. Pasajes: (Madrid: Alianza Editorial, 1976) 195-204. Las citas coresponden a esta edicion. 
que sigo escribiendo y que ya no es eso que sigue ahí pero dónde, cómo (196).

\section{De la representación mental a la representación figurativa}

Este relato corresponde al proceso de reflexión del protagonista, un recorrido a través de sus pensamientos y la evocación de sus sueños. La narración, tarea agobiante, supone un proceso de liberación. La escritura, en tanto actividad cognitiva de puesta en discurso de una representación mental, desemboca en la materialización de imágenes en forma de texto y cumple así una doble función: liberadora porque, escribiendo, el protagonista se deshace de una obsesión, comprende, y, finalmente, adopta una posición cierta respecto al fenómeno vivido. Por otra parte, la escritura, al obligar a conceptuar y organizar un saber, identifica lo desconocido, constituye un esfuerzo de elaboración de una representación más clara de lo ocurrido en el sueño.

Escribir es fijar en el papel las imágenes mentales concebidas, reunir indicios y sensaciones en un todo de significación coherente. Resulta una aventura intelectual que pretende conciliar dos niveles: transitar por la esfera de lo sensorial hasta desembocar en el código racional; es igualmente una forma de comprobar la existencia real de las experiencias oníricas; pero también — por interpelación- es la búsqueda de discursos legitimadores, compañeros solidarios, es decir, lectores que hayan compartido el mismo tipo de experiencia.

La trama narrativa se construye engarzando una secuencia de evocaciones de acontecimientos pasados y, principalmente, alrededor de un acontecimiento perturbador, pero de carácter habitual. La escritura en sí forma parte de la acción, una acción crucial vivida y buscada por el protagonista. El relato describe el proceso de escritura reveladora, cuya finalidad trasciende la evocación de un acontecimiento psicológico singular, «los sueños» y se vuelve reactualización de los hechos; la explicitación verbal permite distinguir las particularidades de lo soñado y sistematizar los conocimientos subyacentes. Al tornar al protagonista hacia esas experiencias oníricas insólitas, la 
elaboración del relato se convierte en el medio de alcanzar el saber deseado. Conduce, entonces, a la aceptación natural de un fenómeno extraordinario, integrando un nuevo saber que va a dominar su existencia; una forma de descubrir la posibilidad de pasar de una realidad a otra, de un lado a otro en busca de la energía que fluye entre los universos.

«Ahí, pero dónde, cómo» presenta una estructura particular. Antes de entrar en el cuerpo del relato se encuentran, a manera de epígrafe, tres breves secciones cuya presencia pareciera casual; pero, como ya lo señaló Borges ${ }^{2}$, aunque «el estilo no parece cuidado», nada es gratuito en la obra de Cortázar. Tales indicios actúan como una especie de guiño al lector al sugerir ser integrados al conjunto de elementos significantes que construyen el sentido global de la historia; se diría una suerte de prólogo codificado secretamente. Primero, un texto relativo a Magritte que encabeza la dedicatoria del libro Bestiario a Paco. La segunda proposición establece una relación lógica fundamental, argumento determinante para explicar la causalidad de la historia: «no depende de la voluntad». Luego, en párrafo separado, se introduce la motivación del relato:

es él bruscamente: ahora (antes de empezar a escribir; la razón de que haya empezado a escribir) o ayer, mañana, no hay ninguna indicación previa él está o no está; ni siquiera puedo decir que viene, no hay llegada ni partida; él es como un puro presente que se manifiesta o no en este presente sucio, lleno de ecos de pasado y obligaciones de futuro (195).

Esa primera parte anticipa el contenido del cuento, esboza vagamente la identidad de una persona, su devenir y su posición en el tiempo. El cuerpo del relato comienza por una puesta en situación que interpela al lector, y combina modos discursivos, enunciación y

2. Jorge Luis Borges. Biblioteca pe'rsomal (Madrid: Alianza Editoral. 1997) 11. 
narración, al servicio de la intensidad creativa y de un efecto persuasivo impactante. El narrador interroga directamente, propone entrar en la diégesis: «A vos que me lees, ¿no te habrá pasado eso que empieza en un sueño y vuelve en muchos sueños, pero no es eso, no es solamente un sueño?» (195).

El texto establece de entrada un contrato de lectura: la necesidad de complicidad entre el lector y el narrador; la invitación a participar activamente en la lectura abre la puerta al universo de conocimientos, experiencias cognitivas y creencias compartidas. El saber proporcionado por las experiencias convocadas, así como la proposición de existencia después de la muerte —o la comprensión de esta creenciatanto como las condiciones de ubicuidad, existencia o no-existencia, resultan indispensables para la programación de la lectura y, en consecuencia, para la construcción de la significación del texto.

En cuanto al cuerpo del relato, este se encuentra segmentado en cinco episodios. El primero, además de plantear vagamente la situación vivida por el protagonista, contiene la introducción y descripción por asociación de Paco, el amigo muerto treinta y un años atrás; introduce una reflexión sobre el acto de escritura y concluye con la descripción detallada del elemento perturbador que genera la trama: el sueño con el amigo muerto. El segundo episodio narra una etapa de reflexión del protagonista y marca una progresión en su proceso de conocimiento, convicción adquirida sobre lo que acontece y lo que sabe. Este empieza a comprender la situación, a analizar el contenido y el carácter iterativo de sus sueños. Algunas referencias cronológicas permiten situar la historia en el tiempo. El tercer episodio, estructurado de modo dialógico, corresponde a una apertura del protagonista: una vez convencido de la realidad del fenómeno vivido en sus sueños, entabla un diálogo con el amigo muerto. Momento relevante en la historia: se cuestiona cuánto ellos están viviendo; pero el narrador, atormentado, sospecha de una verdad o realidad que se le escapa. El cuarto episodio restablece el diálogo con el lector, contiene algunas conclusiones sobre las propiedades del espacio ocupado por Paco y 
cierra el cuento. Termina interpelando al lector y explicitando su objetivo de compartir esta experiencia y de mostrar, por la fuerza de las evocaciones realizadas, la existencia de otra realidad, aún cuando describirla con precisión resulte casi imposible.

\section{Juegos temporales}

Estrechamente vinculado al ejercicio lúdico de reconstrucción espacial se concibe la estructura temporal del relato, cuyos componentes participan de manera indisoluble del enigma textual. El tiempo del relato coincide con el momento de la escritura: es la duración de la rememoración de los sueños y de su puesta sobre el papel. La inexistencia de precisiones cronológicas marcadas, indicios pertinentes, en lo que al tiempo de la escritura se refiere, impide la elaboración de hipótesis concernientes a la duración de la narración. El tiempo de la historia puede ser calculado a partir de indicios dispersos en el texto.

Evidentemente, el juego se abre con la invitación a efectuar las operaciones mentales necesarias para situar sobre una escala cronológica el tiempo de la historia y el tiempo de la palabra a partir de las escasas referencias temporales absolutas: Paco murió treinta y un años antes del tiempo del relato; el narrador protagonista intuye la presencia de su amigo en París hacia los años cincuenta, esto es, quince años después de la muerte de Paco. Se deduce, entonces, que la muerte acaeció en los alrededores del año 1935 y el narrador cuenta la historia hacia el año 1965. Como es habitual en sus cuentos, Cortázar desafía al lector a efectuar una importante inversión de trabajo mental para seguir pistas y procurarse las precisiones necesarias para reconstruir el eje temporal de la historia.

Como parte del contrato de lectura, otra forma de juegos referenciales con el tiempo concierne al empleo distintivo de los tiempos verbales; el presente de indicativo juega un rol particular en este cuento: funciona como un mecanismo para validar y actualizar las percepciones inconscientes vividas en los sueños y para hacer verosímil la presencia del amigo muerto. Eso aparece claramente en los 


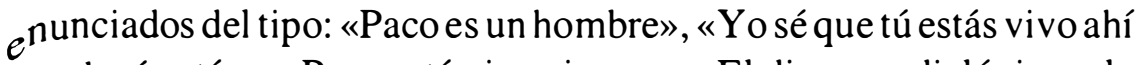
donde tú estás», «Paco está vivo siempre». El discurso dialógico y la ¡dentificación son mecanismos de validación del «propósito».

En este caso, la distinción aspectual perfectivo versus imperfec¡j vo no distingue funcionalmente un rol de primer plano y uno de segundo plano. Los acontecimientos de la trama narrativa que constituyen el primer plano, dado su carácter repetitivo, son relatados mayoritariamente en presente de indicativo, lo cual marca una coincidencia entre el tiempo de la enunciación y el tiempo del enunciado:

si escribo es porque sé, aunque no pueda explicarme qué es eso que sé y apenas consiga separar lo más grueso, poner de un lado los sueños y del otro a Paco, pero hay que hacerlo si un día, si ahora mismo en cualquier momento alcanzo a manotear más lejos. Sé que sueño con Paco puesto que la lógica, puesto que los muertos no andan por la calle y hay un océano de agua y de tiempo (197).

Las situaciones, estados, comentarios o explicaciones que constituyen el segundo plano están igualmente en presente: «Paco está vivo» [...] «el sueño es la única zona donde puedo verte» (200). La explotación del valor de verdad atribuida, en este caso, al uso del presente, contribuye a la validación de la hipótesis cortazariana.

Otras veces el segundo plano se manifiesta con ausencia total de marcaje verbal, lo cual corresponde a la voluntad de crear ambigüedad e imprecisión:

noción de territorio contiguo, de pieza de al lado; tiempo de al lado; y a la vez nada de eso, demasiado fácil para refugiarse en lo binario [...] pero tratar de decirlo de otra manera, insistir: por esperanza, buscando en el laboratorio de medianoche (201).

De manera recurrente, se instaura un juego de evocaciones y no de aserciones, que sugiere un modelo transgresor de codificación de 
la información carente de las relaciones lógicas básicas: sujeto y entorno actancial, espacio-temporales, causa-consecuencia, de identificación, de finalidad, entre otras. Así, la yuxtaposición de una serie de proposiciones constituidas por sintagmas nominales evoca la existencia de otro espacio en otra dimensión, al no indicarse acciones en un tiempo preciso, no se afirma ni se asegura, pero se sugiere, no obstante: nombrar es dar existencia.

\section{Reconstrucción del espacio: convocación de indicios diversos}

El espacio textual, totalmente determinado por el punto de vista adoptado por el narrador, corresponde a una focalización interna; se trata de un narrador intradiegético: el protagonista mismo, un traductor argentino radicado en Europa, cuenta la historia tamizada por el filtro de su obsesión. El procedimiento discursivo empleado para su caracterización omite operaciones de identificación: nombrar, caracterizar física y psicológicamente, recurso cortazariano muy típico. Se privilegia el aspecto mental del protagonista, se le conoce por su intensa actividad reflexiva, y, básicamente, en el proceso de conceptualización de una idea. De hecho, el relato se construye sobre la base de un sistema lúdico que establece un movimiento regular de ida y vuelta, un ir y venir, entre las reflexiones y percepciones de un hombre que entra en contacto con su anigo muerto en Argentina treinta y un años antes con respecto al tiempo de enunciación del relato. Se trata, pues, de un juego de asociaciones sensoriales y de constataciones contradictorias, es decir, de operaciones cognitivas complejas que no logran la identificación de una realidad.

El protagonista, estático, no se desplaza, hace muy pocas actividades, parece permanecer en un solo espacio, en diálogo permanente consigo mismo, como un medio de revitalizar y de poner en claro sus percepciones. Toda su energía está orientada hacia un esfuerzo por reconstruir un espacio: identificar el lugar donde se encuentra su amigo, lugar que el personaje-narrador percibe sin llegar a determinar ni localizar explícitamente. Así, dos espacios —uno perceptual e 
inmediato, imperceptible el otro, lejano y próximo a la vez- son puestos en relación desde el principio. El texto postula la identificación de un lugar no visible pero próximo, ligado al espacio inmediato y cotidiano del protagonista, y la localización de una entidad en ese lugar. La reconstrucción de ese sitio imaginario, su conceptualización, se dificulta, ya que los puntos que sirven para fijarlo son insuficientemente conocidos y, además, discontinuos. En otros términos, las localizaciones específicas de Paco, el amigo muerto, corresponden a coordenadas lejanas, puntos diferentes en tiempos también diferentes, lo cual impide concebir un espacio homogéneo para traerlo y situarlo en la actualidad del protagonista, anclaje referencial de la historia.

Desde el punto de vista cognitivo, la operación lógica de localización en el espacio supone la identificación de dos nociones: el tema y el relatum ${ }^{3}$. El tema —entidad localizada — y el relatum —entidad con respecto a la cual se localiza el sujeto, según el punto de vista del sujeto que quiere efectuar la localización-, no se encuentran en el mismo plano, en un primer sentido del término. La puesta en relación de los tres elementos - tema, relatum y punto de vista-, que determinaría esta relación espacial, se imposibilita, ya que contradice la lógica de las coordenadas espaciales; en consecuencia, el espacio ocupado por Paco sigue estando indeterminado entre el aquí cotidiano y el más allá, aunque el límite entre uno y otro se disuelve por momentos.

\section{El espacio inicial, lo inmediato}

Este relato se inicia situando al narrador protagonista en su universo de cada día: desde el interior de una habitación de hotel

3. Las lenguas naturales tienen diferentes formas de codificar el concepto de espacio. Como las descripciones espaciales son tipicamente organizadas en un nivel abstracto. las opciones escogidas en un contexto particular en una lengua especifica son a menudo convencionales. Desde el punto de vista semántico, para describir el lugar ocupado por una entidad en un espacio hace falta un punto de referencia, el cual debe situarse fuera del dominio del discurso. de manera que sea fácilmente identificable. La localización espacial supone una relación abstracta establecida entre dos entidades: esta relación identifica una entidad localizada. «el tema», y otra con respecto a la cual el sujeto es localizado, «el relatum». Cf. Angelica Becker. Mary Carroll, Ann Kelly, "Reference to spatial relations» en Second Ianguage ac quisition by adults Immingrants. Final report. Reference to space (1988). 
evocará el territorio que le obsesiona y, a partir de ahí, habrá que situar las referencias deícticas. El protagonista anímicamente perturbado, víctima de las sensaciones matinales provocadas por el sabor que deja una pesadilla, evoca un acontecimiento crucial pero, al mismo tiempo, inaprensible, alrededor del cual va a desarrollarse la historia, estructurada, esencialmente, por el descubrimiento de un trayecto espacial en la confluencia del sueño y la realidad:

¿no te habrá pasado eso que empieza en un sueño y vuelve en muchos sueños pero no es eso, no es solamente un sueño? Algo que está ahí pero dónde, cómo; algo que pasa soñando, claro, puro sueño pero después también ahí de otra manera porque blando y lleno de agujeros pero ahí mientras te cepillás los dientes, en el fondo de la taza del lavabo (195).

Desde el punto de vista cognitivo, se plantea un problema de percepción de un lugar y la dificultad de localización de una entidad en el mismo. El conflicto surge de la carencia de los conocimientos básicos necesarios para identificar y relacionar los elementos en cuestión. Se trata de un espacio no identificado, más bien percibido vagamente, en forma sensorial, desde un espacio inicial cerrado, blando, poroso, lleno de agujeros. Sólo la aceptación natural de la presencia de algo concebido primeramente en un sueño permitiría la postulación de la existencia de espacios permeables que se mezclan o funden: «sé que estás vivo ahí donde estás, en una tierra que es esta tierra y no una esfera astral o un limbo abominable» (202).

El texto propone la identificación de ese trayecto orientado hacia un «ahí», elemento recurrente, el cual remite a un espacio con respecto al origo deíctico, frente a la mirada del locutor en el eje sagital en dirección hacia «adelante». En español, «ahí» puede indicar una distancia visualizada como intermedia entre el aquí, lugar del enunciador y el allá, espacio designado como lejano al sujeto hablante. El deíctico «ahí», en el relato, sugiere un espacio imperceptible, pero 
sentido como próximo por su relación con el imaginario mental, implica la reconstrucción de un espacio mental - a partir de una información complementaria- en el cual tiene lugar el contacto entre los dos amigos: Este último pertenece a la experiencia inconsciente del escritor, de modo que el pasaje de la información del inconsciente al consciente puede hacerse en la medida en que esa información se integra a su universo de creencias. Y así, el texto postula un principio fundamental para desentrañar el sentido: la existencia de un saber compartido (escritor-lector) necesario a la competencia interpretativa.

El espacio que obsesiona al protagonista, y cuya creación constituye el eje estructurante del relato, percibido en un espacio mental subjetivo, viene del inconsciente; va adquiriendo forma al despertar por la mañana en la reconstrucción de las imágenes oníricas, y se instala progresivamente en su mundo cotidiano hasta invadir el entorno inmediato. El texto programa un sistema relacional de referencias susceptibles de contribuir a la búsqueda del elemento a situar, a partir del punto de referencia fijado de manera contextual por las acciones realizadas por el protagonista en su entorno cotidiano y donde los objetos domésticos actúan como referentes. Estas referencias obligan a inferir una localización de la situación inicial en un sitio interior como una habitación. En principio, en ausencia de otros elementos que permitan establecer la referencialidad del «ahí», este debería remitir a una región situada en el espacio visual inmediato del hablante (narrador): «¿Por qué otra vez Paco esta noche, ahora que lo escribo en esta misma pieza, al lado de esta misma cama donde las sábanas marcan el hueco de mi cuerpo?» (196).

A pesar de que la información se amplía por la introducción del nuevo personaje, apenas nombrado, el texto juega con lo no dicho, denota ausencia de conocimiento. La información nueva es introducida lacónicamente, recurriendo a una elipsis, se omite la acción realizada por la entidad introducida; el enunciado precedente (un sintagma nominal) indica ciertos parámetros de la situación: quién, dónde y cuándo. El qué permanece velado: «Porque otra vez + Paco 
+ esta noche + esta pieza...» Los componentes del enunciado y su contenido informacional: se nombra una persona: Paco / acción: no hay; debe inferirse / recurrencia, marcaje del carácter habitual de una acción a inferir $=$ otra vez / situación temporal $=$ esta noche $/$ localización espacial = pieza, cama.

Esta construcción autoriza la inferencia de la posible presencia o aparición de una entidad, «Paco», en la pieza del locutor. El procedimiento discursivo de creación de la cohesión textual se basa en dos estrategias, primera, nombrar, dar existencia, y segunda, la yuxtaposición de elementos susceptibles de entrar en relación lógica, pero eludiendo explicitar el vínculo entre ellos. La acción concerniente a Paco no se manifiesta en la proposición, así se crea la ambigüedad y un efecto de suspenso.

\section{El espacio abierto, convocación de lo ausente}

Aducir pruebas de aire, montoncitos de ceniza como pruebas, seguridades de agujero.

En el complejo sistema referencial se integran paulatinamente elementos nuevos. A medida que avanza el relato se develan las localizaciones geográficas que constituyen los referentes que demarcan el universo del protagonista y con respecto a las cuales el espacio indeterminado podría ser identificado. Esas localizaciones actúan como puntos de referencia por medio de los cuales el relatum será puesto en relación para identificar y precisar el espacio señalado por el deíctico «ahí»:

en la conferencia de Ginebra [...] leeré las noticias de Chile [...] salta de la cama a la máquina, de la casa de la calle Rivadabia donde acabo de estar con Paco, a esta máquina que no servirá de nada, ahora que estoy despierto y sé que han pasado treinta y un años (196). 
El texto establece la rel ación espacial existente entre el protagonista, sujeto A, que percibe la imagen del sujeto B, su amigo, cuya localización conocida corresponde al pasado; por el contrario, la localización conocida de A es actual, se encuentra en Ginebra en un cuarto de hotel; «A» trata de precisar y de retener la imagen de «B» descubriendo un inventario de imágenes del pasado: el amigo moribundo en una cama de un cuarto de la calle Rivadabia, la muerte y el cementerio, treinta y un años atrás. La configuración espacial del relato sugiere la asociación, a través de un viaje en el tiempo y en el espacio, de una serie de propiedades en principio contradictorias atribuidas a Paco: «está aquí ahora y vivo». Sin embargo, antes estaba muerto, allá lejos. Así se identifican los elementos que esbozan la ubicación de Paco: un sujeto, dos estados, dos tiempos, dos espacios, conjunto que determina la ocurrencia más allá de las leyes naturales y que explica el pasaje de una realidad del sueño a las palabras: «el agujero entre lo que todavía sigue aquí pero se va entregando más y más a los nítidos filos de las cosas de este lado [...] ahí pero dónde, cómo» (196).

Poco a poco ese espacio soñado adquiere fuerza, toma forma, se proyecta y se instala en la realidad de manera imprecisa pero contundente; se queda en un nivel perceptual ambiguo; pero, creando una nueva dimensión, cobra su lugar en el mundo inmediato y preciso del protagonista, y logra ser identificado: «de este lado». La conceptualización de esa zona particular empezó a construirse a partir de la representación de un espacio mental, cuya génesis responde a la focalización de indicios identificados primero en el sueño, luego recordados y finalmente fijados en el texto. Así entran en juego: un recuerdo nostálgico, un barrio en Argentina, treinta y un años antes del tiempo del relato. Entre estos indicios se establece una relación de correferencialidad de «ahí» con la calle Rivadabia en Argentina, segundo valor referencial de ese deíctico. El «ahí» del espacio inicial no remite al mismo referente que precisa el espacio geográfico; pero, en razón de las características contextuales se puede situar aproximadamente el relatum. «Ahí» 
es un relatum que va a delimitar dos zonas diferentes del espacio. El sujeto por localizar, Paco, escapa a una localización específica, conocida, exacta, el lenguaje carece de los medios que permitan la estructuración de tal espacio.

Por otra parte, «ahí» posee un valor polisémico, puede designar una multiplicidad de puntos intermedios sobre un horizonte amplio, comprendido entre el «aquí» y el «allá». Por oposición a «aquí», deíctico estático y marca en este cuento una referencia espacial ya conquistada y ubicada bajo el dominio del sujeto, «ahí» y «allá» son formas deícticas dinámicas, que abren nuevas regiones a conquistar. El narrador recurre a la polisemia de «ahí» porque contiene exactamente la problemática de focalización de un punto y la posibilidad de significar espacios diversos.

En un esfuerzo por precisar la zona en que se halla su amigo, el protagonista se entrega a una tarea de recuperación, de reconstruir y de reunir todos los elementos susceptibles de contribuir a la elucidación del enigma; convoca una serie de elementos ausentes, establece una relación entre el sueño y la realidad, la permanencia de una realidad dentro de otra, cual universos porosos cuyos elementos se transmutan: «pero con Paco es como si despertara también conmigo». Surge, entonces, la pregunta, ¿pero dónde? Luego sobreviene el recuerdo constante: una imagen de su cara de moribundo, la enfermedad, el sufrimiento, en su cama en una casa de la calle Rivadabia, en el barrio del Once.

En general, la percepción, como fenómeno cognitivo, está ligada a la experiencia del mundo y a la posibilidad de negociación referencial que integran dos sujetos implicados en una comunicación. Una verdadera localización depende del conocimiento que se posea de los objetos que sc quieren poner en relación y de sus características. En este cuento se plantea un problema de percepción, que surge porque el sujeto por localizar ha muerto treinta y un años antes del tiempo del relato: son difíciles de percibir tanto el sujeto como la región que élocupa en el espacio y, poresto, solo se posibilita una designación vaga con un «ahí». 
Además, el intervalo temporal en el cual se fija la imagen del amigo muerto no coincide con el presente del protagonista, lo cual muestra el desplazamiento insólito realizado por la imagen obsesionante, ya que el «ahí» solo adquiere sentido plenamente con información contextual complementaria.

La lógica de los acontecimientos del relato desafía el orden normal de la experiencia del lector: la información procurada resulta insuficiente para identificar el sitio en cuestión. En síntesis, en el espacio geográfico entran en relación los dos mundos designados por la expresión «de este lado», que tendría, al igual que «ahí», un doble contenido semántico: primero, en lo que se refiere al espacio geográfico, Ginebra con respecto a Argentina y segundo, «de este lado» de la realidad, lógica conocida y aceptada, con respecto al otro lado de la realidad donde se encuentra Paco (en Argentina muerto o vivo en una zona imprecisa, sin fronteras fijas). Pero pareciera que «de este lado», zona incierta descubierta en el texto, se conceptualiza por la sumatoria de los posibles, más allá del lenguaje y de la lógica misma que convoca las coordenadas espacio-temporales de la referencia deíctica.

El título mismo, portador de sentido, encierra la configuración básica del proceso de reconstrucción del itinerario de conceptualización del espacio en este relato. El contenido semántico de cada elemento, tributario de una imagen particular, así como la interacción de los componentes semánticos, proponen una forma de enfocar el espacio: «ahí» puede designar una infinidad de puntos en un horizonte; pero aporta un argumento complementario en el sentido de una conclusión de mayor peso ${ }^{4}$. «Dónde» y «cómo» implican una demanda de información precisa y complementaria para situar el territorio por conquistar. En otras palabras, desde el título, el narrador enuncia dos posiciones complementarias en cuanto a su propósito. Por un lado, evoca el espacio vagamente visualizado, por otro, busca y demanda la información cierta para identificar el «ahí». Tal configuración se

$4 \quad$ Jean Michel Adjam. Eléments de Linguistique textueile (Liège: Pırre Mardaga. edıtor, i 990) 
convierte en lema, en estrategia recurrente y obsesiva a lo largo de todo el texto.

Por otra parte, «ahí» también funciona como un conectador de cooperación, reactiva la atención del interlocutor y la orientación hacia los puntos de referencia sucesivos de la descripción espacial.En este texto el lector es frecuentemente llamado a participar en la conceptualización del espacio, el narrador lo interpela de manera directa:

a vos no te ocurre como a mí [...] a lo mejor vos que me lees tratás de fijar con una salmodia lo que se te va yendo, repetís estúpidamente un verso infantil, arañita visita, arañita visita, cerrando los ojos para centrar la escena capital del sueño deshilachado (197).

\section{Recuperación del espacio: trayectos de certeza}

En el proceso de conocimiento surgen visos de certidumbre. El protagonista desentraña lo acaecido aun cuando no puede reconocer exactamente el lugar en que se encuentra su amigo; comienza a tener la certeza de estar descubriendo algo, pasa de la impresión al razonamiento, conceptualiza con vaguedad un lugar e intuye la posibilidad de precisión:

en cualquier momento empiezo a manotear más lejos. Sé que sueño con Paco puesto que la lógica, puesto que los muertos no andan por la calle y hay un océano de agua y de tiempo entre este hotel en Ginebra y su casa de la calle Rivadavia, entre su casa de la calle Rivadavia y él muerto hace treinta y un años. Entonces es obvio que Paco está vivo (de qué inútil, horrible manera tendré que decirlo para acercarme, para ganar algo de terreno) mientras yo duermo; eso que se llama soñar (197).

Esta secuencia introduce un episodio narrativo en el cual el protagonista confronta realidades, descodifica el significado de las experiencias vividas; pareciera reconocer la existencia real del amigo 
en sus sueños. Un complejo juego de procedimientos discursivos y scmánticos es activado para organizar subversivamente el contenido proposicional de cada uno de los enunciados, creando así una ambigüedad que fundamenta lo fantástico. La secuencia en cuestión incluyc las siguientes proposiciones: «sé que sueño con Paco», «los muertos no andan por la calle» (distancia física y temporal: EuropaAmérica; hoy-ayer), razonamientos que al final llevan a la convicción «él está muerto». Sorpresivamente, el enunciado siguiente porta una deducción lógica pero en el sentido inverso: «es evidente que está vivo». Tal disposición de los enunciados produce una ruptura de continuidad y favorece la interpretación que se fundamenta en el principio de contigüidad semántica, el cual postula la asociación de conceptos ordenados según una relación de contigüidad que programa tanto su interpretación como su memorización en el momento de la interpretación del significado de un texto. De esta manera, para interpretar la situación, el lector retiene la confrontación de verdades en la oposición: está muerto / es evidente que está vivo. Seguidamente, aparece un enunciado entre paréntesis que contiene una reflexión sobre el proceso de conocimiento, y funciona como elemento distractor. Tal distracción se logra por medio de un procedimiento discursivo, en el cual un enunciado intercalado interfiere en la organización sintáctica alejando al predicado del sujeto, produciendo una fragmentación del significado: «entonces es obvio que Paco está vivo (de qué inútil, horrible manera tendré que decirlo para acercarme, para ganar algo de terreno) mientras yo duermo; eso que se llama soñar» (197).

Como se puede ver, la segunda parte de esta proposición, directamente dependiente de la primera, queda lejos de la misma, y favorece así la ambigüedad interpretativa al anular los principios de contigüidad semántica y provocar la ruptura de la cohesión. La construcción de la proposición favorece una interpretación equívoca y, al mismo tiempo, permite elaborar el sentido de lo acaecido, la ambigüedad, el pasaje del sueño a la realidad: la creación de un espacio fantástico particular donde se cruzan dos dimensiones. 
De esa forma, el universo textual postula el sueño como un estado de actividad mental, un espacio de conocimiento: «vuelvo a saber mientras duermo». En el pasaje citado el procedimiento para crear lo fantástico consiste en la contradicción del saber: el protagonista acepta la muerte de Paco, sin embargo, luego dice que está vivo, y aunque lo sabe en un espacio lo reconoce en otro. El cuestionamiento de la realidad como proceso de conocimiento alcanza un punto culminante en la siguiente secuencia:

Lo que entonces sé es que haber soñado no es más que parte de algo diferente, una especie de superposición, una zona otra, aunque la expresión sea incorrecta pero también hay que superponer o violar las palabras si quiero acercarme, si espero alguna vez estar (198).

Efectivamente, el texto evoluciona del análisis de un hecho puntual difuso hacia la certeza, el espacio que obsesiona al narrador: se vislumbra como un espacio diferente del habitual donde la idea de superposición de lugares resulta concebible. Pero, además, el hecho puntual conduce a un hallazgo fundamental concerniente a la percepción de la realidad misma. Este nuevo orden viene de la necesidad de transgresión e implica, necesariamente, una violación del lenguaje. Si el lenguaje supone una representación del mundo según la experiencia ordinaria de un universo de creencias, para conceptuar y expresar algo diferente, fuera de la norma, como el fenómeno del que se ocupa el cuento, es decir, la concepción de «otra zona», en otra dimensión al mismo tiempo paralela al mundo real, es necesario, entonces, reinventar el lenguaje y decir, de esta manera, con el narrador «una zona otra», aunque tal expresión sea incorrecta: se revela aquí la insuficiencia misma del lenguaje ante lo no convencional.

A medida que el relato avanza, la convocación de la presencia de Paco, aunque siempre difusa, toma fuerza logrando adquirir contornos de certeza; el contacto con Paco deja de ser solamente una experiencia onírica: 
Gruesamente, como lo estoy sintiendo ahora, Paco está vivo aunque se va a morir, y si algo sé es que no hay nada de sobrenatural en eso [...] bastó el primer sueño para que yo lo supiera vivo más allá o más acá del sueño (198).

La recurrencia del empleo de «ahí» evoca su valor indicial; el texto supone un diálogo con el lector, este valor constituye un elemento que contribuye a dar existencia al universo espacial evocado; y es, en razón de ese diálogo, que se justifica el empleo de «ahí».

El tercer episodio contiene una suerte de confirmación y de validación de las experiencias precedentes. El relato sugiere los desplazamientos de Paco, sus trayectos insólitos, itinerarios fuera de lo normal: vivió y murió en Argentina y, sin embargo, viene a reunirse con su amigo quien se encuentra de «el otro lado», en Ginebra. El protagonista comienza a aceptar la presencia de Paco en otro espacio diferente del que le corresponde, y a aceptar también la existencia de otra realidad donde se permitiría establecer una relación de contigüidad entre los espacios que entran en juego en el texto. La determinación de esta contigüidad hace suponer, entonces, una relación de proximidad entre los dos amigos, pues además del contacto físico o visual, abren un diálogo, en el cual el protagonista acepta a Paco como un interlocutor real, compartiendo las experiencias vividas en el presente del mismo modo en que lo hicieron en el pasado, y por ende transgrediendo las determinaciones lógicas de las coordenadas espacio-temporales:

Ves, eso es lo que sé, no es mucho pero lo cambia todo. Me aburren las hipótesis tempo espaciales, las $n$ dimensiones sin hablar de la jerga ocultista, la vida astral y Gustav Meyrinck. No voy a salir a buscar porque me sé incapaz de ilusión o quizá, en el mejor de los casos, de la capacidad para entrar en territorios diferentes. Simplemente estoy aquí y dispuesto. Paco, escribiendo lo que una vez más hemos vivido juntos mientras yo 
dormía; si en algo puedo ayudarte es en saber que no sos solamente mi sueño que es un ahí pero dónde, cómo, que ahí estás vivo y sufriendo. De ese ahí no puedo decir nada, sino que se me da soñando y despierto, que es un ahí sin asidero (199).

Aparentemente, se plantea la incapacidad de dinamismo, de búsqueda, la condición esencialmente estática impuesta por la concepción de una realidad basada en las tres dimensiones lógicamente aceptadas, aún cuando la existencia de territorios y realidades diferentes invaden el mundo ordinario. El protagonista renuncia a la búsqueda, a pesar de perseguir su objetivo de liberación por la escritura y asumir así la presencia real de su amigo. Al final casi derrotado, contra su voluntad dice poco del espacio inaccesible. Las experiencias vividas en los sueños no le proporcionan información suficiente para delimitar las propiedades del espacio sospechado como un «ahí»; y, sin embargo, en un intento desesperado por plasmar la figuración de sus representaciones mentales, procede a descartar los indicios lógicos que ubicarían a su amigo en el lugar correspondiente en el universo racional convencional.

no te creo en el infierno [...] por qué estás vivo ahí donde estás si de nuevo te vas a morir [...].

Por supuesto que no estás en la casa de la calle Rivadabia, y que yo en Ginebra no he subido la escalera de tu casa en Buenos Aires, eso es utilería del sueño y como siempre al despertar las imágenes se deslíen y solamente quedás vos de este lado, vos que no sos un sueño, que me has estado esperando en tantos sueños pero como quien se cita en un lugar neutral (200).

No obstante, al final, se manifiesta implícitamente el pasaje de Paco: queda de este lado, aunque sus movimientos no sean explícitos ni intervenga la voluntad de los personajes para que el desplazamiento se efectúe. Una fuerza exterior provoca los acontecimientos, lo cual se 
infiere por la selección de los verbos que expresan el fenómeno: «se me da soñando», "quedás de este lado». Ocurre algo cuyo origen y causalidad son desconocidos, no se llega a saber nunca el porqué, el personaje tampoco lo sabe. El proyecto de acción nunca es focalizado, se trata más bien de algo que ha acaecido y no de una acción controlada. Además, fuera de la actividad de escritura, el protagonista no hace nada, está completamente invadido por esta presencia, su existencia en tanto que ser humano permanece en la sombra, no lo conocemos ni se da a conocer. Es un personaje sin carácter; el cuento se circunscribe a un momento de su vida, una obsesión. Su hacer se limita a actividades mentales: saber, soñar, pensar, evocar, ver.

\section{Las operaciones de localización}

Como seguir, hacer trizas la razón repitiendo que no es solamente un sueño.

En su propuesta interpretativa, el texto convoca operaciones encadenadas entre sí para trazar un trayecto espacial constituido por una sucesión discontinua de visiones portadoras de diferentes referencias espaciales. Es el caso, por una parte, de la evocación del pasado del amigo vivo, enfermo, muerto y, por otra, la vivencia del sueño que aporta otro punto de vista constituido por una sola visión, la del espacio inaprensible. Algunas impresiones subjetivas son indicios susceptibles de contribuir a la configuración de ese espacio percibido como incierto, propuesto por el texto:

como quien se cita en un lugar neutral, una estación o un café (200).

el sueño es la única zona donde puedo verte (200).

noción de territorio contiguo, de pieza de al lado (201). 
seguir por mi vereda como vos por la tuya (202).

sé que estás vivo ahí donde estás, en una tierra que es esta tierra y no una esfera astral o un limbo abominable; y la alegría dura y está aquí mientras escribo (202).

Alrededor de indicios caracterizados por el rasgo semántico común de la «indeterminación» se construyen los conceptos antes citados para describir el trayecto espacial que culmina en la concepción aproximativa de un espacio vecino borroso, de fronteras indefinibles. El lugar, aunque caracterizado por rasgos particulares como neutralidad, proximidad, cotidianeidad e imprecisión, trasciende su existencia onírica y se fija en el mundo de la vigilia. La búsqueda de ese espacio se hace igualmente por la palabra, como si la descripción lingüística determinara la posibilidad de crear una representación mental: «tratar de decirlo de otra manera, insistir» (201). Al respecto Charles Grivel señala que escribir es «comme un désir du papier [...] celui de faire advenir de 'l'impensé', de l'incongru, de l'impossible. Faire advenir: c'est à dire, représenter» ${ }^{5}$.

La rememoración de la casa de Paco surge también como una operación de localización; como una forma de organizar la búsqueda de su amigo, el protagonista evoca todas las características que definen el lugar donde él se encontraba, la última referencia espacial asociada a él en el pasado. El protagonista en tanto que sujeto cognitivo es responsable del conocimiento de los lugares. Se trata de un espacio que corresponde también a su juventud, tiene de allí, pues, múltiples puntos de referencia por ser un lugar conocido. El procedimiento de rememoración se presenta como un mecanismo que le permitiría a Paco franquear una frontera: la estrecha escalera de esa casa / las piezas de alto cielo raso y estucos amarillos. A pesar de la acumulación de indicios, el texto apenas sugiere la representación mental del

5. Charles Grivel, Fantastique-Fiction (Paris: PUF. 1992) 37. 
espacio buscado, sin llegar a construir una representación figurativa bien precisa ${ }^{6}$.

La construcción de la aventura fantástica del cuento «Ahí, pero dónde, cómo» responde a una confrontación de la lógica de percepción de las relaciones espaciales, según Vandeloise ${ }^{7}$, en función de la complejidad presentada por las relaciones espaciales postuladas. Los objetos localizados son idealizados en función de la perspectiva desde la cual son observados. Así, para subrayar algunas cualidades de esos objetos, se dejan en la vaguedad otras. Tal fenómeno perceptivo se desarrolla plenamente en este cuento, en el cual el protagonista identifica a su amigo en una zona incierta, lo considera desde una perspectiva particular nutrida de elementos intrínsecos: está muerto y, sin embargo, está vivo, idea obsesionante, único punto de interés focalizado; nada aparte de Paco tiene importancia en esta historia. El proyecto de localización desde su inicio está, «racionalmente», condenado al fracaso, las informaciones atestadas como verídicas, en lo que concierne al amigo muerto, suponen descalificar una localización convencional, según el conocimiento normal y lógico del mundo. La imposibilidad de localización surge porque «la región» que debe funcionar como «relatum» no posee las propiedades necesarias para asumir esta función: estable, sólida, de posición conocida; si ese conocimiento extralingüístico sobre el espacio falta, la relación espacial no se puede establecer. En consecuencia, el conflicto aquí, esencialmente, consiste en que los conocimientos y las creencias sobre el espacio avistado superan la experiencia personal que permite conceptuar y hacer la correspondiente descripción lingüística. Un universo nuevo, poroso y permeable, no pensado, paralelo u otro cuya representación no ha sido aún integrada al imaginario social, y en

6. Coincidimos aqui con los principios de Louis Diguer. Schéma narratif é individualité (París: PUF, 1993) 31. según los cuales. la representación mental es un producto cuya existencia se deduce por la observación de lo que hace un sujeto. es el modo de existencia psiquica de los objetos. de los comportamientos de uno mismo y de los demás. La representación figurativa es una imagen puesta delante de la mirada interior y que se puede extraer por introspección.

7. Claude Vandeloise. L'espace en fiangais (París: Seuil. 1986). 
consecuencia, integrado al universo de la palabra. Un lugar tal solo puede ser identificado por la diferencia, lo no conocido, lo otro; el cuento lo logra en el laboratorio de medianoche, el espacio imaginario conquista el espacio textual.

Invita así el texto a una transmutación, a repensar si «las cosas son exactamente como nos han enseñado», a realizar un transgresor ejercicio, a emprender la aventura de desmitificar la validez de las coordenadas convencionales, estables; a borrar fronteras, irrumpir y, entonces, capturar, apropiarse de la energía que fluye del otro lado, ¡ahí... donde relincha el unicornio! 